\title{
Visualization of regulations to support design and quality control - a long-term study
}

\author{
Mikael Bloméa, ${ }^{*}$ \\ ${ }^{a}$ Ergonomics and Aerosol Technology, Department of Design Sciences, Faculty of Engineering, Lund University, \\ P.O. Box 118, SE-22100 Lund, Sweden
}

\begin{abstract}
The aim of the study was to visualize design regulations of furniture by means of interactive technology based on earlier studies and practical examples. The usage of the visualized regulations was evaluated on two occasions: at the start when the first set of regulations was presented, and after six years of usage of all regulations. The visualized regulations were the result of a design process involving experts and potential users in collaboration with IKEA of Sweden AB. The evaluations by the different users showed a very positive response to using visualized regulations. The participative approach, combining expertise in specific regulations with visualization of guidelines, resulted in clear presentations of important regulations, and great attitudes among the users. These kinds of visualizations have proved to be applicable in a variety of product areas at IKEA, with a potential for further dissemination. It is likely that the approaches to design and visualized regulations in this case study could function in other branches.
\end{abstract}

Keywords: Learning tool, human computer interaction, participatory ergonomics, product design, visualization

\section{Introduction}

Regulations are used in information and quality management systems to ensure high quality by supporting design, production and communication processes. These regulations can be presented as a conventional system on an intranet suitable for printouts, visualized as a traditional text-based report with a list of headings accompanied by tables and pictures, or presented as paper documents in manuals or binders. Such approaches do not always correspond to some companies' requirements for usability. The extensive documentation of quality management systems can appear meaningless and time consuming to the users $[1,2,3]$. Web technology, however, can be used to visualize and let users interact with the information through hyperlinked text, pictures, and animations. The potential for multimedia in ISO 9000 quality systems is, according to a study by Edwards and Gibson [1], particularly apparent when it comes to training exercises, which can include com- petency and assessment requirements, and which are available quickly and conveniently at any location.

A case study in collaboration with Saab Automobile resulted in an interactive multimedia system of visualized ergonomic guidelines [4]. The system was, in general, faster to use with lower dispersion in performance speed and number of incorrect answers compared to the conventional system.

The aim of this study was to visualize several modules of different design regulations for furniture at IKEA of Sweden (IoS) using the same approach as in the Saab Automobile case and carry out a short and long-term evaluation of the usage of the visualized regulations.

\section{Materials and methods}

\subsection{Visualization of regulations}

A field study was carried out at the Laws \& Standards Department at IKEA of Sweden (IoS) AB. The

\footnotetext{
${ }^{*}$ Corresponding author. E-mail: Mikael.Blome@design.lth.se
} 
purpose was to explore the preferable manner for visualizing the product regulations to be used in the education of representatives of people working at different levels in the production process. It was decided to try out the visualization process on one product segment and to perform an initial evaluation of this module of visualized regulations, and then continue with other product segments resulting in new modules.

The existing regulations presented in traditional text documents with headings, text blocks, tables, photos and black and white drawings were visualized according to principles from similar visualization studies $[4,5,6]$. This involved combinations of pictures, animated scenarios and models with text and hyperlinks. The visualized regulations of each product segment were designed in an interactive presentation module viewable with Flash Player according to an interactive participatory visualization process, see Figure 1.

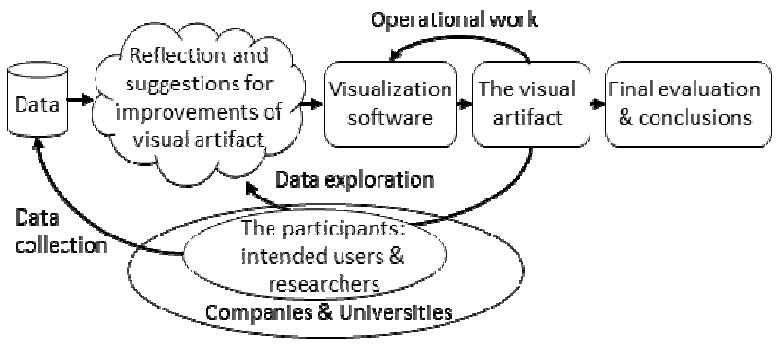

Fig.1. The visualization process [5].

\subsection{Subjects}

The subjects consisted of colleagues and managers at the Laws \& Standards Department at IoS, and users who received the visualized regulations from Laws \& Standards Department at IoS.

\subsection{Procedure}

Each module of visualized regulations (the visual artifact in Figure 1) was developed by the author in discussion with the person responsible for the specific regulations at IoS who had extensive experience in formulating and communicating such regulations. The author contributed with examples from earlier case studies (e.g. [4,6]) and the IoS representative contributed the specific regulations, practical examples, situations and intended use.

The first set of visualized regulations was evaluated during an education day at the Laws \& Standards Department by nine male subjects, representing different but relevant positions with respect to present and future usage [7]. This and the following regulations were evaluated six years later by users via a questionnaire.

\section{Results}

\subsection{The interactive prototype}

The regulations were visualized with illustrations and animations, enlargement of details, testing equipment and scenarios, see Figure 2.

\subsection{Preliminary outcome}

A preliminary evaluation of the results from the discussions and the questionnaire shows a very positive response among the users as well as the responsible persons at Laws \& Standards Department at IoS. The evaluation when the first module was presented showed that it was easy to learn and would be most helpful in teaching others about the regulations. The users requested to have immediate access to that set of visualized regulations [7]. The second evaluation, six years later, showed that all except one of the visualized regulations was still in use. 

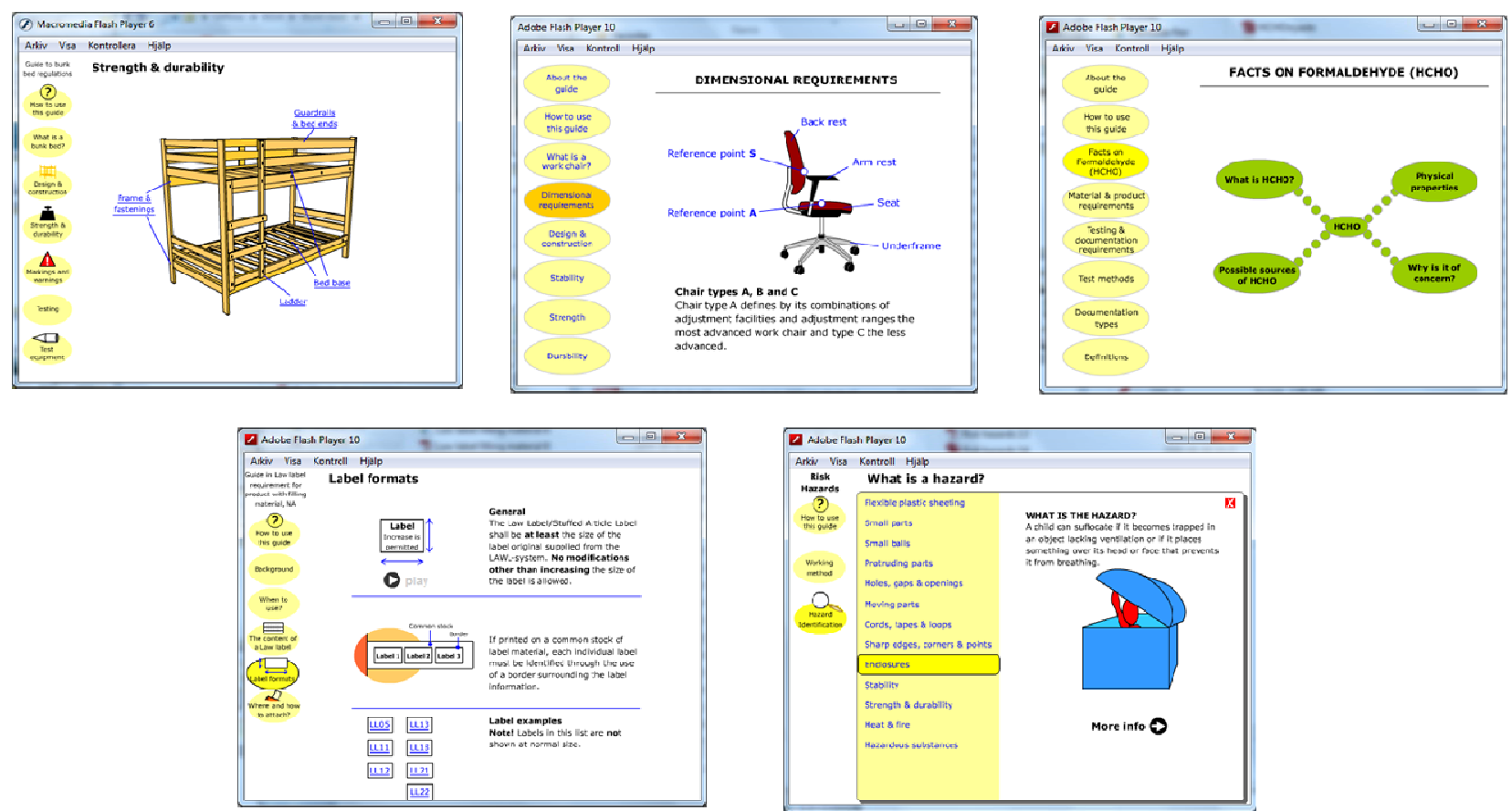

Fig. 2. Screenshots of five interactive regulations: bunk beds, work chairs, formaldehyde, law labels and risk hazards.

\section{Discussion}

The evaluations by the users showed a very positive response to using visualized regulations. The participative approach combining expertise in specific regulations with visualization of guidelines resulted in clear presentations of important regulations, and great attitudes among the users. These kinds of visualizations have proved to be applicable in a variety of product areas at IKEA, with a potential for further dissemination. It is likely that the approaches to design and visualized regulations in this case study could function in other branches. It would also be valuable to further analyze the evaluation questionnaire and carry out additional interviews among users to enhance the design process of visualized regulations.

\section{Acknowledgement}

This research was performed in collaboration with the Laws \& Standards Department of IKEA of Sweden.

\section{References}

[1] J. Edwards and P.R. Gibson, Integrated multi-media computers in the execution of ISO 9000 quality system requirements for document control and training, Computers and Industrial Engineering, 32 (3) (1997), 529-538.

[2] J. Karltun, J. Axelsson and J. Eklund, Working conditions and effects of ISO 9000 in six furniture making companies: implementation and processes, Applied Ergonomics, 29 (4) (1998), 225-232.

[3] A.K. Chaudhuri and U.H. Acharya, Measuring effectiveness and suitability of a quality system, Total Quality Management, 11 (2) (2000), 149-153.

[4] M. Blomé, C. R. Johansson and P. Odenrick, Visualization of ergonomic guidelines - A comparison of two computer aided systems to support vehicle design, International Journal of Industrial Ergonomics, 36 (2006), 571-580.

[5] M. Blomé, Visualization of guidelines on computer networks to support processes of design and quality control, Ph.D. Dissertation, University of Lund, Sweden, 2004.

[6] M. Blomé, C.R. Johansson and P. Odenrick, Computer supported visualisation of quality systems developed by network teams, Applied Ergonomics, 34 (3) (2003), 239-247.

[7] M. Blomé, Visualization of regulations to support design and quality control, in: Proceedings of the IEA2006 Congress Meeting Diversity in Ergonomics, Maastricht, The Netherlands. 